\title{
Personalidade e Comparecimento Eleitoral na América Latina: Efeitos de Características Psicológicas Individuais em Contextos de Obrigatoriedade*
}

\author{
Ednaldo Aparecido Ribeiro ${ }^{1}$ \\ Julian Borba ${ }^{2}$ \\ ${ }^{1}$ Professor Associado do Departamento de Ciências Sociais da Universidade Estadual de Maringá. \\ Maringá, PR. Brasil. \\ E-mail: ednaldoribeiro@icloud.com, https:/ /orcid.org/0000-0002-4005-5108 \\ ${ }^{2}$ Professor de Ciência Política do Departamento de Sociologia e Política da Universidade Federal de Santa \\ Catarina (UFSC). Florianópolis, SC. Brasil. \\ E-mail: borbajulian@yahoo.com.br, https://orcid.org/0000-0002-0149-6533

\section{INTRODUÇÃO}

$\mathrm{O}$ expressivo volume de pesquisas dedicadas à identificação dos condicionantes do comparecimento eleitoral é reflexo da centralidade dessa forma de envolvimento político nas democracias contemporâneas. Essas pesquisas têm se concentrado sobre os efeitos de fatores de âmbito individual, tais como educação, renda, estado civil, crenças e valores que os cidadãos nutrem para com o regime democrático, entre outras (Denny e Doyle, 2008; Gallego, 2010), mas também sobre condicionantes estruturais, como o nível de desenvolvimento econômico dos países e características institucionais (Geys, 2006; Blais, 2006).

Tratando mais especificamente da vertente que enfatiza a dimensão individual do fenômeno, alguns investigadores têm procurado incorporar em seus modelos explicativos dimensões psicológicas relativas às diferenças individuais. Goldberg (1992) considerou essa ordem de

\footnotetext{
* Os autores agradecem aos pareceristas anônimos pelas sugestões e críticas que contribuíram para o aprimoramento deste artigo. Também agradecem ao Conselho Nacional de Desenvolvimento Científico e Tecnológico (CNPq), Coordenação de Aperfeiçoamento de Pessoal de Nível Superior (Capes)-Programa Nacional de Cooperação Acadêmica (Procad) e à Fundação Araucária pelo apoio financeiro que viabilizou a realização da pesquisa.
}

DADOS, Rio de Janeiro, vol.62(4):e20170048, 2019. 
fatores na análise dos determinantes do voto nas eleições gerais britânicas de 1997, comparando os efeitos de traços de personalidade com aqueles produzidos por um dos mais importantes preditores desse tipo de comportamento: a escolaridade. Os resultados revelaram que os indicadores mais relevantes são "trabalhador versus preguiçoso" e "calmo versus agressivo", sendo que os mais trabalhadores e os mais agressivos apresentaram maior propensão ao voto. De forma geral, com a inclusão dos traços ocorre considerável redução dos efeitos da escolaridade em todos os modelos propostos. O já mencionado estudo de Denny e Doyle (2008), usando dados longitudinais do National Child Development Study (NCDS), investiga os determinantes individuais da participação eleitoral em 1997 nas eleições gerais britânicas e identifica que alguns traços de personalidade afetam de forma significativa o comparecimento, mesmo tendo seus efeitos controlados por outras importantes variáveis preditoras. Gerber, Green e Larimer (2008), utilizando procedimento experimental verificaram um expressivo efeito de características de personalidade sobre a probabilidade de comparecimento entre eleitores norte-americanos. Gerber et al. (2011) e também Mondak (2010) chegaram a conclusões semelhantes a respeito do efeito de traços como extroversão, estabilidade emocional e abertura à experiência.

Todos esses trabalhos pioneiros nessa interface entre Ciência Política e Psicologia, entretanto, se concentram sobre casos de democracias com longo histórico de desenvolvimento e nas quais o voto é facultativo. Nos últimos anos pesquisas importantes sobre condicionantes e efeitos da obrigatoriedade do voto têm sido desenvolvidas, inclusive no contexto latino-americano (Weitz-Shapiro e Winters, 2011) e, mais especificamente, sobre nossa realidade nacional (De Leon e Rizzi, 2016; Cepaluni e Hidalgo, 2016; Holbein e Rangel, 2016). Entretanto, apesar de alguns deles tocarem em pontos ligados a características psicológicas, como a satisfação com a vida (Weitz-Shapiro e Winters, 2011) ou interesse e conhecimento político (Holbein e Rangel, 2016), desconhecemos estudos que tratem especificamente dos efeitos de traços de personalidade sobre a probabilidade de comparecimento aos locais de votação em países com voto obrigatório.

Ainda que as punições para o não comparecimento sejam de forma geral brandas e com efeitos distintos sobre diferentes camadas populacionais (Cepaluni e Hidalgo, 2016), é plausível supor que os efeitos dos traços de personalidade identificados pelos estudos men- 
cionados anteriormente sejam sensivelmente distintos quando essa dimensão institucional é considerada nos modelos de análise. O traço da conscienciosidade, um dos analisados neste artigo e relativo a um padrão rígido de obediência às regras, por exemplo, possivelmente tende a ter o seu efeito potencialidade nos contextos em que existe uma lei que obrigue os indivíduos a comparecerem aos locais de votação. A extroversão, frequentemente associada a maior ativismo político, pode também ter seu impacto sensivelmente reduzido quando uma legislação passa a obrigar todos os cidadãos a adotar esse comportamento.

O presente artigo pretende ser uma contribuição para a discussão sobre a relevância dessas diferenças psicológicas individuais nesses contextos particulares à região latino-americana. $\mathrm{O}$ material empírico utilizado nos testes foi retirado do Latin American Public Opinion Project (LAPOP) em sua rodada de 2010, na qual foi inserida uma bateria de questões sobre traços de personalidade a partir da abordagem proposta por Costa e McCrae (2003). Dentre os países que fizeram parte da pesquisa do LAPOP, há 13 em que o comparecimento é previsto em lei e outros três em que o voto é facultativo, desta forma, além de possibilitar a identificação de efeitos gerais dos traços de personalidade sobre o comparecimento, permite avaliar a existência de impactos diferenciados em razão de regras institucionais distintas.

Os resultados encontrados confirmam a relevância dos traços de personalidade apontada pela literatura recente, mas acrescentam ao debate evidências sobre efeitos diferenciais entre países que adotam a obrigatoriedade e aqueles que facultam o comparecimento aos seus cidadãos. Como iremos demonstrar, nesses últimos os efeitos dessas diferenças psicológicas individuais tendem a ser maiores.

Para atingir esse objetivo dividimos o texto em quatro partes fundamentais. Na primeira delas definimos personalidade em sua manifestação como objeto empírico, discutindo seus conteúdos e os procedimentos empregados para a sua mensuração. A segunda seção discute a relevância dessas particularidades psicológicas individuais para a explicação do comparecimento eleitoral. Na sequência, são apresentadas as hipóteses, os dados utilizados e os procedimentos metodológicos empregados. A quarta seção expõe e discute os resultados encontrados. Finalmente, são oferecidas algumas considerações finais. 


\section{A PERSONALIDADE COMO CONCEITO E OBJETO EMPÍRICO}

Nos limites deste artigo entendemos personalidade como uma estrutura interna (ou psicológica) multifacetada e durável, fortemente influenciada por fatores biológicos e com potencial influência sobre os comportamentos individuais (Mondak, 2010) ${ }^{1}$. A sua natureza multifacetada nos remete ao conceito de fatores de personalidade, que podem ser entendidos como as categorias básicas de diferenciação individual em funcionamento que, em razão da sua natureza observável, normalmente são expressos pelos observadores em geral através de adjetivos (Winter, 2003).

Para Costa e McCrae (2003) um modelo altamente compreensivo e hierarquizado para a descrição e compreensão da estrutura da personalidade poderia ser composto por apenas cinco grandes fatores: abertura à experiência, conscienciosidade, extroversão, sociabilidade e estabilidade emocional.

O primeiro desses fatores, abertura à experiência, foi definido por Costa e McCrae (2003) como uma multifacetada dimensão que inclui inteligência, percepção, sensibilidade estética e uma atração intrínseca para novas experiências. Esse grande fator é o que mais tensão exerce sobre os limites da linguagem, sendo impossível a sua redução a uma única palavra como é usual em abordagens léxicas como a Big Five. Para se referir a alguém com baixa pontuação nessa dimensão, Costa e McCrae (2003) se valem de frases como "insensível em relação às artes e à beleza" e "entendiado por discussões de ideias". Esse traço tem sido investigado de forma mais recorrente por pesquisadores preocupados com o mundo do trabalho, sendo associado principalmente a comportamentos criativos no exercício das atividades laborais, mas também à baixa lealdade para com as organizações (Moss et al., 2007) e facilidade de adaptação a atividades produtivas internacionais (Huang, Chi e Lawler, 2005). Para além do ambiente de trabalho, essa característica tem também sido associada a comportamentos de risco, como a combinação de álcool e direção, e também ao tabagismo (Booth-Kwley e Vickers, 1994).

A conscienciosidade, por sua vez, envolveria características ligadas à confiabilidade, tais como "organização", "pontualidade" e "confiável" e alguns autores tendem a incluir também um conteúdo volitivo com termos como "trabalhador" e "perseverante" (Mondak, 2010). 
De forma previsível, pesquisas identificaram a associação desse traço com alto rendimento e produtividade no trabalho (Dudley et al., 2006). Em estudo conduzido em laboratório, Horn, Nelson e Brannick (2004) encontraram forte ligação entre conscienciosidade e comportamento honesto em diferentes situações simuladas. No campo da saúde existem evidências de que indivíduos com alta pontuação nesse componente tendem a adotar estilos de vida mais saudáveis, especialmente no que diz respeito à atividade física regular e apresentam expectativa de vida superior à média (Friedman et al., 1993).

O fator extroversão é o que possui a mais longa história na Psicologia das diferenças individuais. Eysenck (1947) incluiu esse traço no seu modelo de dois fatores e Cattell (1956) em seu já mencionado instrumento de 16 traços (16PF). Os principais adjetivos utilizados para representar esse componente são "energético", "arrojado", "falante" e, é claro, "extrovertido" (Mondak, 2010). No ambiente de trabalho o traço tem sido associado a forte comprometimento organizacional e tendência à compulsão pelo trabalho (Burke, Matthiesen e Pallesen, 2006). O sucesso profissional em áreas ligadas a vendas e habilidades acadêmicas também tem sido associado a altas pontuações nesse fator (Pulford e Sohal, 2006).

A sociabilidade, por sua vez, é o fator com menor tradição de pesquisa e as evidências empíricas acerca de seus efeitos também são reduzidas. Envolve basicamente uma disposição favorável ao estabelecimento de relações interpessoais positivas e os instrumentos utilizados para mensurá-lo normalmente se valem de termos como "caloroso", "amável" e "simpático" (Mondak, 2010). No trabalho, indivíduos com pontuação alta nesse fator tendem a apresentar maior facilidade em atividades em grupo e maior adaptabilidade em novas ocupações (Barrick e Mount, 1991), bem como maior estabilidade na carreira (Laursen, Pulkkinen e Adams, 2002). No campo da saúde foram encontradas associações com baixas taxas de alcoolismo e depressão (Id.).

A estabilidade emocional, por fim, possui tradição tão longa quanto a extroversão. Tupes e Christal (1961) já incluíam em seus instrumentos de pesquisa subfatores para mensurar essa dimensão entre recrutas das forças armadas norte-americanas. Os adjetivos utilizados atualmente nos instrumentos de mensuração são "calmo", "relaxado", "estável" (Mondak, 2010). Diferentemente do que vimos nos outros 
fatores, esse último não tem apresentado efeitos significativos em fenômenos ligados ao ambiente de trabalho, mas em compensação tem apresentado implicações médicas sérias, tais como propensão a altos níveis de estresse, tensão e depressão quando são verificadas baixas pontuações (Bolger e Schilling, 1991).

Em termos empíricos, existem dois tipos de investigação sobre esses componentes, que se distinguem sobretudo em relação às estratégias de mensuração empregadas para construção dos seus indicadores (Mondak, 2010). No primeiro grupo estão as pesquisas que se concentram nas propriedades dos próprios fatores, procurando confirmar a sua real existência, identificar seus elementos subsidiários e demonstrar a sua validade em diferentes contextos culturais e linguísticos. No segundo grupo encontram-se pesquisas que partem do pressuposto da existência dessa estrutura de cinco grandes fatores para investigar suas consequências e efeitos sobre atitudes e comportamentos.

Em razão dos seus objetivos, os pesquisadores do primeiro grupo costumam se valer de escalas bastante amplas, como Costa e McCrae (2003) que utilizam um instrumento com 240 itens e Goldberg (1992) que adota uma bateria de 50 itens em pesquisas com pequenas amostras.

Nas pesquisas aplicadas do segundo grupo, em razão dos seus objetivos e limitações, o emprego de baterias longas é inviável, especialmente porque, em paralelo à mensuração dos componentes, devem ser coletadas todas as informações referentes às atitudes e comportamentos que serão associados à estrutura de personalidade no momento da análise. Além disso, como se trata de pesquisas que pretendem testar associações ou efeitos em uma dada população, precisam adotar procedimentos amostrais rigorosos, o que implica trabalhar com grandes amostras. O tempo de aplicação de instrumentos em número considerável de sujeitos leva à necessária redução das baterias sobre personalidade para reduzir o tempo necessário à coleta de dados.

Na construção dessas baterias reduzidas normalmente são utilizadas escalas bipolares ou de diferenciação semântica que contrastam pares de adjetivos, vinculando-se assim à perspectiva lexicológica nos estudos sobre personalidade, que defende a captação dos fatores pela sua expressão na linguagem coloquial (Mondak, 2010). Em termos práticos esses instrumentos apresentam aos participantes da 
pesquisa um conjunto variado de escalas cujos polos são representados por adjetivos contrastantes, como "falante/calado", "extrovertido/introvertido", "organizado/desorganizado", entre outros. Os entrevistados são convidados a se autoavaliarem e escolherem um ponto na escala de 0 a 10 entre esses polos. O instrumento de 16 itens, desenvolvido por Cattell (1956), já empregava essa abordagem de pares contrastantes e até hoje esse tem sido o formato mais utilizado nas pesquisas aplicadas ${ }^{2}$.

Como esclareceremos adiante na seção metodológica, em nossa pesquisa foram utilizados dados produzidos com o emprego de uma bateria de dez itens, sendo cada traço composto por duas escalas com pares de adjetivos contrastantes.

\section{PERSONALIDADE E COMPARECIMENTO ELEITORAL}

O estudo das relações entre características psicológicas individuais e fenômenos políticos mais gerais tem uma longa história. Considerando apenas as principais contribuições do século XX, merecem ser mencionados os estudos baseados em psicobiografias sobre elites (George e George, 1964; Renshon, 1995; Greenstein, 2003; Erikson, 1969), as pesquisas sobre aderência a valores democráticos (Adorno, 1950; Eysenck; 1954; Stenner, 2005) e também as investigações sobre tolerância e dogmatismo (Rokeach, 1960).

Os estudos que se concentram sobre o comportamento político, todavia, possuem uma trajetória bem mais recente e somente na última década começaram a ser publicados trabalhos incorporando a chamada psicologia das diferenças individuais em pesquisas sobre acesso à informação, frequência de discussão sobre política, interesse por política, contatos com autoridades, participação em campanhas, engajamento em formas contestatórias de manifestação e, o que nos interessa particularmente, o comparecimento eleitoral.

Destacamos primeiramente o estudo de Fowler e Kam (2006), que, apesar de não utilizar o arcabouço conceitual e metodológico das abordagens baseado nos grandes fatores, merece atenção pelo seu pioneirismo, já que foi o primeiro trabalho publicado a explorar a relação entre particularidades psicológicas e a decisão por comparecer aos locais de votação. 
O ponto de partida dos autores é o pressuposto derivado da teoria da escolha racional de que o comparecimento é influenciado pelos custos envolvidos na busca e processamento de informações sobre as candidaturas e pelos benefícios esperados com o resultado eleitoral (Franklin e Grier, 1997; Highton, 1997; Jackson, 2000). A novidade proposta pelos autores diz respeito à consideração dos diferentes momentos ou tempos em que os custos e benefícios emergem, já que os primeiros seriam pagos antes ou durante as eleições, enquanto os benefícios "[...] podem não se materializar até vários dias, meses ou mesmo anos após o dia das eleições" (Fowler e Kam, 2006:114). Essa diferença temporal supostamente poderia favorecer o envolvimento de indivíduos que manifestam com maior intensidade a virtude da paciência, ou seja, apresentam maior tolerância na espera por benefícios de médio e longo prazo. Portanto, o traço de personalidade focalizado por esses pesquisadores, apesar de não usar exatamente essa terminologia, seria a paciência.

Para testar suas hipóteses os autores utilizaram um experimento de laboratório baseado em uma série de perguntas aplicadas por computador a uma amostra de 235 sujeitos recrutados entre alunos de graduação, em maio de 2004. Inicialmente os voluntários eram interrogados sobre o comparecimento nas eleições primárias estaduais que haviam ocorrido dois meses antes (março de 2014) e também sobre características sociodemográficas. Ao final do questionário cada entrevistado era informado que havia sido selecionado para ganhar um prêmio e então levado a fazer uma série de escolhas entre US\$ 100,00 a serem pagos em 30 dias ou um valor maior em prazos variáveis que poderiam chegar a 60 dias. Assim, os entrevistados que concordavam com tempos maiores de espera para recebimento da recompensa monetária eram aqueles com maior pontuação em uma escala de paciência (Fowler e Kam, 2006).

Os resultados encontrados primeiramente confirmam que o nível de paciência não estava correlacionado com nenhuma das características sociodemográficas avaliadas, entretanto, estava ligado à manifestação de maior interesse por política, sugerindo assim que indivíduos mais orientados para recompensas futuras tendem a prestar mais atenção aos assuntos dessa natureza, que em geral envolvem processos de tomada de decisões que apenas no longo prazo afetam a vida cotidiana dos cidadãos (Id.). 
O mais importante achado, entretanto, diz respeito ao relacionamento estatisticamente significativo entre a escala de paciência e o comparecimento eleitoral, indicando que indivíduos que apresentam nível de paciência acima da média apresentam taxa de envolvimento nas eleições de $26 \%$, contra $16 \%$ daqueles que apresentam paciência abaixo da média. Os entrevistados que optaram pelo prêmio entregue no menor prazo (30 dias) apresentam apenas 13\% de comparecimento. Em modelos multivariados que possibilitaram o controle dessa relação por variáveis sociodemográficas e atitudinais relevantes, o impacto da paciência continuou efetivo e a diferença nas taxas de envolvimento entre os menos e os mais pacientes chegou a 23\% (Id.). Os autores concluem que a paciência pode ser entendida como uma virtude política e que, apesar de terem focalizado apenas os seus efeitos sobre o comparecimento, suspeitam que pode ser igualmente relevante para outras formas de participação política.

Apesar de também não usar o aporte teórico e metodológico das abordagens dos grandes fatores, o artigo de Gerber et al. (2008) pode também ser incluído nessa revisão por incorporar aos modelos explicativos do comparecimento a predisposição psicológica à obediência às normas sociais, que potencializaria a compreensão do ato de votar como um dever cívico. Apesar de ser facilmente aceitável a hipótese de que indivíduos mais respeitosos às regras sociais tenham maior disposição para o envolvimento nas eleições, mesmo considerando o peso relativamente baixo de cada voto para os resultados finais, os autores afirmam que a literatura especializada tem falhado na incorporação desse fator ético nas suas explicações predominante orientadas por abordagens racionalistas.

Vasta literatura na psicologia social tem atestado a influência dos mecanismos de internalização e coerção sobre uma ampla variedade de comportamentos, indicando que as pessoas são bastante atentas a modelos de comportamento que são claramente considerados apropriados pelo grupo social a que pertencem (Scheff, 2000), especialmente quando existem sinais de vigilância, ainda que velada, a respeito da adequação das ações individuais ao padrão socialmente aceito (Posner e Rasmusen, 1999).

No campo político existem apenas indícios de que sanções não violentas podem auxiliar na conformação de comportamentos socialmente reconhecidos, como no caso exemplar da legislação eleitoral 
italiana, que até pouco tempo atrás previa a obrigatoriedade. A punição estabelecida nesse contexto, aparentemente inócuo, consistia na publicação do nome dos "não votantes" em um mural no centro das cidades e era suficiente, segundo relatos dos próprios eleitores, para dificultar a busca por um emprego, configurando o que os autores chamam de "a shaming policy" (Gerber et al., 2008).

O quanto essas estratégias de coerção são realmente efetivas sobre o envolvimento dos eleitores nos processos eleitorais, entretanto, é algo que permaneceu inexplorado em termos empíricos e a proposta de Gerber e seus colaboradores foi justamente oferecer uma contribuição nesse sentido. Para atingir esse objetivo incorporam essa tendência à obediência e conformação às normas como um elemento do cálculo racional que leva à decisão pela participação ou abstenção. Já que o voto é universalmente considerado um dever cívico, no cálculo do comparecimento o benefício esperado é a satisfação de exercer um dever cívico que pode se reverter em aceitação e apreço social. Nestes termos, propõe a hipótese de que o comparecimento ocorre, apesar de punições relativamente brandas em termos legais, porque os eleitores "[...] estão dispostos a pagar os reduzidos custos de tempo e esforço para evitar o sentimento de vergonha associado a não votar ou, inversamente, para desfrutar da satisfação de votar" (Ibid.:35).

Para testar essa hipótese os pesquisadores propõem um experimento de campo conduzido no estado de Michigan antes das eleições primárias que ocorreram em agosto de 2006, nas quais estavam em disputa cargos para condados, cidades e distritos. A amostra foi composta por mais de 180 mil domicílios em todo o estado, a partir de uma lista oficial de pessoas qualificadas para votar com endereços postais válidos. Após a seleção os domicílios foram separados aleatoriamente em cinco grupos, um para controle e quatro para diferentes tratamentos.

O grupo de controle, como é usual, não recebeu qualquer estímulo da equipe de pesquisadores. Os domicílios do primeiro grupo de tratamento, que serviriam de base de comparação para os demais, recebiam uma correspondência reafirmando o ato de votar como um dever cívico através de frases como "cumpra o seu dever cívico vote!". No segundo grupo de tratamento, além dessa reafirmação também era oferecido um estímulo de tipo Hawthorme na forma da frase "você está sendo estudado!" e que o seu comportamento eleitoral poderia ser analisado por meio dos registros públicos da justiça 
eleitoral mesmo respeitando o sigilo do voto. Tomando o primeiro grupo como base de comparação, o objetivo com esse novo incentivo era identificar o quanto a percepção de que estava sendo observado impactaria a sua propensão a agir em consonância com a norma social que estabelece o comparecimento como desejável. O terceiro grupo de tratamento recebia uma correspondência com a informação sobre os votantes no domicílio nas eleições anteriores, em 2004. Nessa lista, a partir de informações públicas da justiça eleitoral, os nomes dos moradores do domicílio que efetivamente compareceram aos locais de votação eram acompanhadas da palavra "votou", enquanto os que não votaram tinham um espaço em branco na frente do nome. Abaixo dessa lista havia a informação de que a equipe iria atualizar esses dados após as eleições de 2006 e uma nova correspondência seria enviada. $\mathrm{O}$ objetivo nesse grupo era verificar se a percepção de que os demais moradores da residência acompanham o comportamento do indivíduo pode exercer algum efeito sobre sua intenção de comparecer. O quarto grupo recebeu uma lista parecida, mas incluindo também os eleitores da vizinhança, além da promessa de que a informação seria atualizada após o novo pleito (Gerber et al., 2008).

Após as eleições as taxas de comparecimento foram calculadas e, entre oseleitores do grupo de controle, chegou a pouco mais de $29 \%$. O grupo que recebeu o reforço do "dever cívico" apresentou comparecimento ligeiramente superior, chegando a 31,5\%. Com a adição do efeito Hawthorme, o terceiro grupo registrou $32,2 \%$, o que implica ganho de 2,5 pontos em relação ao grupo de controle. As maiores elevações, entretanto, foram verificadas nos dois últimos grupos, com $34,5 \%$ e $37,8 \%$, respectivamente. Entre os que receberam informações sobre a votação das pessoas que fazem parte do seu domicílio, portanto, o aumento foi de 4,9\% e, entre aqueles que receberam informações semelhantes da sua vizinhança, a elevação chegou a $8,1 \%$ (Id.).

Tais resultados sugerem primeiramente que a identificação do voto como um dever cívico favorece o comparecimento e que em associação com a pressão social do grupo tende a potencializar esse efeito. Essa primeira conclusão é particularmente relevante para a formulação de nossa hipótese fundamental sobre o efeito do traço da conscienciosidade sobre o engajamento eleitoral, pois, se o sentimento de dever moral é algo relevante em termos gerais, é possível supor que seja ainda mais relevante entre indivíduos que apresentam características psicológicas que favorecem a obediência e a internalização das normas sociais. 
Mais próximo da perspectiva que adotamos em nossa pesquisa, o artigo de Denny e Doyle (2008) contribui para a compreensão dessa relação entre traços psicológicos individuais e a decisão pelo comparecimento às urnas no contexto britânico (eleições nacionais de 1997), usando a série de dados longitudinais do National Child Development Survey. A abordagem psicométrica empregada pelos autores, baseada na proposta lexical de Goldberg (1992), apesar de se aproximar da que adotamos, utiliza pares de traços discordantes distintos: cauteloso/impulsivo, temperamental/equilibrado, tímido/agressivo, flexível/rígido, sociável/retraído e preguiçoso/trabalhador.

Os resultados encontrados por meio de modelo probit indicam que, apesar de controlados por importantes variáveis sobre habilidades cognitivas e interesse por política, os efeitos de dois traços de personalidade são estatisticamente significativos. Indivíduos que são mais "trabalhadores" (em oposição aos "preguiçosos") e os que são mais "equilibrados" (em oposição aos "temperamentais") têm sua probabilidade de comparecimento elevada em pouco mais de 1\%. Para os autores em ambos os casos os efeitos eram esperados, pois: 1) o ato de votar implica custos e esforços pessoais, como busca por informações acerca dos candidatos e o deslocamento até os locais de votação, favorecendo o envolvimento dos mais esforçados e menos preguiçosos; 2) o voto, ainda que não obrigatório no Reino Unido, é um comportamento socialmente incentivado e aqueles que se apresentam como "equilibrados" tendem a manifestar adesão a esses padrões de ação valorizados socialmente (Denny e Doyle, 2008).

Resultados ainda mais interessantes são obtidos quando os autores retiram a variável de interesse por política dos modelos, por suspeitarem de problemas de endogeneidade entre ela e o comparecimento. Sem a presença desse preditor, além da manutenção dos efeitos dos dois traços mencionados anteriormente, a característica "agressivo" passa a exercer efeito significativo. A diferença de probabilidade de comparecimento entre o mais tímido e o mais agressivo atinge 8 pontos percentuais. Segundo os autores a razão para esse efeito passa pela tendência desses últimos em manifestarem suas posições de forma mais ostensiva, inclusive pelo voto (Id.). Em síntese, esse trabalho confirma a relevância desses traços psicológicos individuais para essa que é a principal forma de ação política nas democracias eleitorais contemporâneas. 
Finalizamos essa revisão com o trabalho de Gerber at al. (2011), (Personality Traits and Participation in Political Processes), que se aproxima de nossa proposta por empregar a abordagem lexical desenvolvida por Costa e McCrae (2003). Esse artigo apresenta duas contribuições fundamentais para essa agenda: 1) distingue os efeitos dos traços de personalidade sobre o comportamento efetivo e sobre a declaração de comparecimento, já que usam dados oficiais de votação; 2) identifica a persistência desses efeitos com controles clássicos da literatura comportamentalista, como educação e renda.

Para os autores algumas características das modalidades de participação política são relevantes para se entender a forma como a personalidade afeta o ativismo: 1) intensidade da interação social envolvida; 2) potencial exposição ao conflito gerada; 3) reconhecimento social da ação como dever cívico; 4) relação entre a ação e potenciais recompensas materiais (Gerber et al., 2011). Alguns atos participativos, portanto, envolveriam maior interação com os indivíduos envolvidos, como manifestações de rua, enquanto outros pressupõem reduzido ou nenhum contato entre os praticantes, como a doação em dinheiro para campanhas. Da mesma forma, algumas modalidades são mais reconhecidas como comportamentos socialmente desejados que outras, podendo algumas serem inclusive desaconselháveis e razões para reprovação social, tais como ocupações de prédios públicos ou bloqueios de vias públicas. Essas duas últimas forças de ação política expõem seus praticantes ao conflito com maior intensidade do que o trabalho voluntário em uma campanha ou o comparecimento a um comício. As recompensas esperadas são igualmente diferentes entre as modalidades, já que o que se espera com um abaixo-assinado para solicitar uma melhoria no atendimento médico em um hospital é bastante distinto na sua extensão e tempo de atendimento daquele que se espera escolhendo esse ou aquele candidato à Presidência da República.

Tratando especificamente do voto em pleitos nacionais os autores afirmam que se trata de uma ação política que envolve reduzida interação social, baixa exposição ao conflito, forte reconhecimento como norma social ligada ao dever cívico e baixo benefício instrumental para os agentes. Esse enquadramento nas dimensões leva à formulação das hipóteses a respeito das relações entre cada traço psicológico e o ato efetivo de comparecer às urnas ou declarar comparecimento (Id.). 
Começando pelo traço da extroversão, como as pessoas que manifestam fortemente essa característica são mais assertivas e sociáveis, é aceitável a expectativa de que se envolvam em modalidades que pressupõem doses elevadas de interação interpessoal. Trabalhos anteriores já atestaram essa relação em modalidades como o envolvimento em campanhas e manifestações em democracias consolidadas e jovens (Mondak et al., 2010), mas falharam na identificação da conexão com o voto (Mondak e Halperin, 2008), possivelmente em razão da natureza solitária e isolada desse ato. Ainda assim, Gerber et al. (2011) propõem a hipótese de que havia uma maior propensão ao comparecimento entre aqueles que manifestam com maior intensidade esse traço, pois, ainda que comparativamente essa modalidade envolva menor interação, a assertividade do traço favoreceria o envolvimento político em geral.

Acerca da sociabilidade, associada a posturas altruístas e modestas, os autores não esperam encontrar relações significativas. A postura cética de Gerber et al. (2011) se deve à ambiguidade dos resultados das pesquisas anteriores sobre esse traço. Por um lado, temos trabalhos associando-o ao envolvimento em organizações não políticas e altos níveis de comparecimento aos locais de votação e, por outro, pesquisas afirmando o seu efeito negativo sobre o ativismo em razão da tendência à negação do conflito (Blais e Labbé-St-Vincent, 2011; Mutz, 2002; Ulbig e Funk, 1999).

Sobre o traço da conscienciosidade, caracterizado sobretudo pela obediência às normas, Gerber et al. (2011) também não esperam encontrar relações consistentes, pois as pesquisas prévias também indicam sinais contraditórios. Se por um lado a internalização das normas sociais por indivíduos com forte pontuação nesse traço favorece o envolvimento nas modalidades revestidas de desejabilidade social, por outro, Mondak et al. (2010) mostraram que também estaria associado ao interesse por ações que geram benefícios instrumentais, favorecendo a participação política em contextos nos quais os indivíduos percebem que a atividade de campanha é importante para a vitória de um candidato do qual se espera resposta para alguma demanda específica. Assim, entre a obediência às normas e a essa expectativa por retornos, os efeitos tenderiam à anulação (Gerber et al., 2011).

Em relação à estabilidade emocional, associada aos autocontroles e à baixa ansiedade e depressão, os autores esperam encontrar efeitos 
positivos, ainda que sutis e variando em razão do grau de competitividade envolvido na disputa, já que essa estabilidade estaria ligada à maior aceitação do conflito (lbid).

Por fim, acerca do traço da abertura a experiências, associado à curiosidade e atração por novas ideias, os pesquisadores não esperam encontrar relações significativas em relação ao voto. Apesar de pesquisas anteriores terem indicado que pontuações elevadas nesse traço potencializariam o engajamento em atividades que envolvem o intercâmbio de ideias como reuniões e debates (Mondak et al., 2010), não existem evidências consistentes sobre efeitos semelhantes em outras modalidades.

Utilizando dados do Cooperative Campaign Analysis Project (CCAP) de 2007-2008, um survey nacional foi aplicado pela internet a uma lista de 20 mil eleitores devidamente registrados para votar, e também de uma pesquisa específica com uma amostra de 1.800 eleitores do estado de Connecticut (CS, Connecticut Survey). Em ambas as fontes de dados existiam informações sobre o voto nas eleições de 2004 e 2006, além daquelas necessárias ao enquadramento dos entrevistados nos cinco traços de personalidade (Ibid). As respostas dos entrevistados sobre o comparecimento foram confirmadas por dados dos órgãos oficiais responsáveis pela condução das eleições.

Os resultados encontrados demonstram claramente a existência de interessantes relacionamentos positivos e estatisticamente significativos entre o comparecimento eleitoral e os traços da extroversão e da estabilidade emocional. O primeiro teste proposto pelos autores envolveu uma medida sobre participação efetiva em quatro eleições nacionais nos dois surveys utilizados, ou seja, um índice de comparecimento efetivo. Mesmo tendo seus efeitos controlados por sexo, raça, idade e localização geográfica, a elevação de dois desvios-padrão na medida de extroversão acarretou incremento de $7,5 \%$ na probabilidade de os entrevistados do CCAP apresentarem alto comparecimento. Entre os entrevistados de Connecticut essa elevação é ainda maior, chegando a quase $10 \%$. Elevações semelhantes são encontradas para o traço da estabilidade emocional, com $14,1 \%$ na amostra do CCAP e $8,9 \%$ no CS. Para melhor avaliar a relevância desse efeito é importante indicar que os autores encontraram percentuais relativamente próximos para renda (18 e 10,9 pontos) e escolaridade (8,7 e 9,9 pontos) em cada um dos dois surveys (Gerber et al., 2011). 
Os resultados envolvendo a medida de conscienciosidade, que nos interessa particularmente, parecem favorecer a hipótese da propensão dos indivíduos que manifestam essa característica psicológica ao envolvimento quando percebem benefícios instrumentais no ato político. Isso porque os autores verificam efeito negativo e estatisticamente significativo entre a pontuação nesse traço e o índice de comparecimento efetivo. Indivíduos que se localizam a dois desvios-padrão na escala de conscienciosidade apresentam probabilidade de fazer parte do grupo com alto comparecimento, 9,3 e 7,9\% maior, respectivamente, para as amostras do CCAP e do CS.

Contrastando esse envolvimento real com a declaração de comparecimento dos entrevistados, os resultados são igualmente interessantes, especialmente quando se trata de entender as discrepâncias entre essas duas medidas. Gerber et al. (2011) identificam que a sobredeclaração (declaração de comparecimento sem efetivamente ter comparecido) está associada com pontuações reduzidas no traço da sociabilidade. Indivíduos que apresentam pontuações reduzidas em dois desvios-padrão nessa escala têm probabilidade 10,1\% maior de apresentar níveis elevados de sobrerrepresentação, o que rivaliza com os efeitos de educação (13,7\%). Esse resultado é explicado pela tendência à modéstia ligada a esse traço, reduzindo a tendência dos indivíduos em afirmarem que fizeram algo, sem efetivamente tê-lo feito, para conquistar apreço social.

Todas as demais associações não alcançaram níveis de significância mínimos exigidos $(0,05)$, mas consideramos que ainda assim merece destaque a relação entre o traço da conscienciosidade e essa sobre-declaração de comparecimento. Os resultados indicam que aqueles que manifestam de forma mais intensa essa característica, ligada à aceitação das normas sociais, têm 7\% mais chance de fazer parte do grupo dos que mais sobredeclararam ter comparecido aos locais de votação. A tendência de internalização e obediência às regras se manifesta, portanto, não apenas no maior comparecimento, mas também no esforço de se adequar ao socialmente desejado, ainda que seja por meio do fornecimento de informação inverídica a um pesquisador (Ibid).

Em resumo, podemos afirmar que o conjunto dos testes propostos por esses autores oferecem abundantes evidências sobre a relevância de diferenças individuais de personalidade para a explicação de padrões de comportamento político. Nas palavras dos autores 
os modelos de participação se beneficiariam da atenção às fontes dessas diferenças que se originam em eventos anteriores àqueles que têm sido tradicionalmente considerados no "funil da causalidade" (Id.:704).

Em conjunto, esses trabalhos corroboram a relevância de esforços de incorporação dessa dimensão psicológica em nossos modelos explicativos, porém pouco podem dizer sobre os efeitos dessa dimensão em diferentes arranjos institucionais, já que foram desenvolvidos no contexto das democracias consolidadas, no qual o comparecimento é facultativo. Como antecipamos na introdução e iremos reiterar mais à frente, pretendemos oferecer duas contribuições principais com este artigo: 1) primeiramente analisamos os efeitos desses traços de personalidade nos contextos das jovens democracias, ainda pouco estudadas por essa literatura de interface entre Ciência Política e Psicologia; 2) verificamos as magnitudes desses efeitos em contextos institucionais distintos no que diz respeito à obrigatoriedade do voto.

\section{ASPECTOS METODOLÓGICOS}

\section{Hipóteses}

As hipóteses testadas neste trabalho envolvem dois dos traços de personalidade propostos pela perspectiva de Costa e McCrae (2003): extroversão e conscienciosidade. A seleção desses dois traços foi inspirada diretamente pelos achados de Gerber et al. (2011) e Denny e Doyle (2008), mas também por serem os componentes que supostamente teriam os seus efeitos mais afetados pela regra institucional da obrigatoriedade. A sensibilidade às normas sociais pontada por Denny e Doyle (2008) tenderia a ser menos relevante em contextos em que todos são obrigados, ainda que essa obrigação não atinja todos da mesma maneira, como demonstraram recentemente Cepaluni e Hidalgo (2016). De forma semelhante, a extroversão que impulsiona o maior ativismo pode perder parte de sua relevância nesse contexto eleitoral. $\mathrm{O}$ mesmo não pode ser dito dos traços da estabilidade emocional, abertura a experiências e sociabilidade, para os quais os achados empíricos até o presente momento são bastante controversos.

Mesmo ao lidarmos com o traço da extroversão, nossas expectativas são ambíguas, pois o mesmo está associado tanto ao desejo de interação interpessoal quanto ao desejo de expressar opiniões. Por um lado, como o voto é um ato político individual e isolado, seria possível 
prever efeitos nulos ou negativos entre a extroversão e o comparecimento. Por outro, como o voto é uma forma de expressão de opiniões e posições, essa característica psicológica poderia estar associada à maior tendência de comparecimento. Resta, portanto, saber qual desses efeitos se sobressai na realidade latino-americana. Para maior clareza, encaminhamos nossos testes no sentido positivo, então nossa primeira hipótese é:

H1: Indivíduos com pontuações elevadas na extroversão apresentam maior probabilidade de comparecimento.

Ainda que o ato de comparecer aos locais de votação e o voto em si sejam uma ação individual, como a extroversão tem sido apontada como um potencializador do ativismo político em geral, julgamos possível formular a hipótese da existência de efeitos diferenciais nos distintos contextos institucionais em razão à obrigatoriedade, pois a transformação dessa ação em obrigação legal pode reduzir a relevância dessa característica psicológica, fazendo com que introvertidos e extrovertidos deixem de se diferenciar. Sendo assim, nossa segunda hipótese é:

\section{H2: Os efeitos da extroversão são maiores em contextos de voto facultativo.}

Passando ao traço da conscenciosidade, como está fortemente ligado à aceitação e internalização às normas sociais (Costa e Mccrae, 2003) e o voto é reconhecido como um dever cívico em diferentes contextos culturais e políticos (Gerber et al., 2008), é plausível supor que, independentemente das configurações legais do voto, indivíduos com pontuações elevadas nesse componente apresentem maior probabilidade de envolvimento nessa modalidade de participação política. Assim, nossa terceira hipótese é:

H3: Indivíduos com pontuações elevadas na conscienciosidade apresentam maior probabilidade de comparecimento.

A intensidade dessa relação, entretanto, pode ser alterada em contextos de obrigatoriedade. Nos contextos em que o comparecimento é ato compulsório esse efeito tende a ser reduzido, pois a obrigação se estende a todos independentemente da sua maior ou menor sensibilidade ao socialmente aceito. É claro que esse efeito depende forte- 
mente da magnitude das punições aplicáveis àqueles que infringem a regra, mas, de qualquer maneira, esse nivelamento provocado pela obrigatoriedade tenderia a diferenciar a relação entre conscienciosidade e comparecimento entre contextos compulsórios e facultativos. Desta forma, nossa última hipótese é:

H4: Os efeitos da conscienciosidade são maiores nos contextos de voto facultativo.

\section{Dados e procedimentos de análise}

Os dados utilizados nos testes foram produzidos pelo Latin American Public Opinion Project em sua edição de 2010. Essa foi a única pesquisa em países latino-americanos que, até o presente momento, aplicou uma escala operacionalizável de identificação dos traços de personalidade em paralelo à coleta de informações sobre comportamentos e atitudes políticas, sendo assim a única fonte disponível para o tipo de pesquisa que propomos. Os países selecionados foram Argentina, Bolívia, Brasil, Chile, Colômbia, Costa Rica, El Salvador, Equador, Guatemala, México, Panamá, Paraguai, Peru, República Dominicana, Uruguai e Venezuela ${ }^{3}$.

Os cinco grandes traços ou fatores da estrutura de personalidade, seguindo as perspectivas lexicológicas propostas por Costa e McCrae (2003) e Goldberg (1992), são captados pelo LAPOP por meio de uma bateria de dez itens que apresentam adjetivos contrastantes, desta forma cada um dos fatores é composto por dois itens. Essa bateria é apresentada aos entrevistados com o seguinte enunciado:

\footnotetext{
Vou mencionar uma série de características de personalidade que podem ou não se aplicar ao(à) sr.(sra.). Usando a escala de 1-7, onde 1 significa "Discordo Muito" e 7 significa "Concordo Muito", por favor me diga qual número melhor indica se o(a) sr. (sra.) concorda ou discorda de cada afirmação. $\mathrm{O}(\mathrm{A})$ sr.(sra.) deve avaliar até que ponto cada par de características se aplica a você, mesmo que uma característica se aplique melhor do que a outra.
}

Os pares de características dos dois fatores aqui utilizados são apresentados abaixo: 
Quadro 1

Fatores e Itens da Personalidade

\begin{tabular}{lc}
\hline Fatores & Itens \\
\hline Extroversão & Pessoa sociável e ativa; Pessoa quieta e tímida \\
Conscienciosidade & $\begin{array}{l}\text { Pessoa de quem se pode depender e discipli- } \\
\text { nada; Pessoa desorganizada e pouco cuidadosa }\end{array}$ \\
\hline Fonte: Questionário Lapop Brasil, 2010.
\end{tabular}

Como os dois itens de cada fator possuem ordens inversas em razão do seu contraste, primeiramente tratamos de recodificar as escalas dos adjetivos "negativos", invertendo sua pontuação para viabilizar posteriormente a construção de uma única medida integrada para cada um dos cinco grandes traços. $\mathrm{O}$ resultado desse procedimento foi a redução dos itens a dois fatores com escalas padronizadas para variarem de 0 a 10. As distribuições dessas variáveis entre os países estão dentro dos padrões de normalidade necessários para a sua inserção em modelos de regressão (entre -1 e 1).

O comparecimento, por sua vez, é medido por uma variável dicotômica ( $0=$ não e $1=$ sim), gerada pela seguinte pergunta: "O(A) sr./sra. votou nas últimas eleições presidenciais de [ano da eleição]?". As frequências dessa variável são apresentadas no início da próxima seção.

Em razão da natureza dicotômica dessa variável foram propostos modelos de regressão logística, portanto, as estimativas geradas dizem respeito aos efeitos dos preditores sobre a probabilidade de ocorrência de comparecimento expressos em exponenciais de B, mas convertidos em percentuais na apresentação. Além dessas estimativas são oferecidas informações sobre níveis de significância e erros padronizados.

Além das variáveis dependentes e independentes foram adicionados nesses modelos alguns controles reconhecidos pela literatura como relevantes na explicação do ato de comparecer.

Procurando contemplar condicionantes apontados pela literatura sobre participação política geral e sobre o comparecimento mais especificamente, primeiramente inserimos nos modelos um conjunto de medidas ligadas aos recursos individuais (Verba, Schlozman e Brady, 
1995; Ribeiro e Borba, 2015; Blais, Gidengil e Nevitte, 2004). Considerando principalmente as evidências recentemente encontradas por Carreras e Castañera-Angarita (2013), introduzimos a escolaridade dos entrevistados (anos de escolaridade completos), como proxy de recursos materiais, e também cognitivos, que poderiam impulsionar o ativismo eleitoral. Ligada a essa dimensão dos recursos, mas também a uma clivagem geracional debatida por Inglehart e Welzel (2009) e Dalton (2015), a idade (anos de vida) também foi considerada um controle relevante em nossa análise. Ainda preocupados com essa dimensão social e econômica ligada aos recursos, julgamos pertinente incluir o sexo (binária, mulheres=1) como uma estratégia de controle dessa persistente clivagem no campo político (Inglehart e Norris, 2003).

Como destacaram Verba, Schlozman e Brady (1995) os recursos individuais não levam ao ativismo se não forem acompanhados de mobilização cognitiva para a política. Desta forma, foram também incluídas medidas de interesse por política (escala de 4 pontos) e eficácia política subjetiva (escala de 7 pontos).

Igualmente importante no modelo do Voluntarismo Cívico proposto em Voice and Equality (Verba, Schlozman e Brady, 1995) são as redes institucionais nas quais os indivíduos são envolvidos, já que poderiam funcionar como estruturas de recrutamento. Inserimos duas variáveis sobre essa dimensão, sendo a primeira delas uma medida derivada da frequência dos entrevistados a reuniões de organizações religiosas, associações de pais e mestres, organizações comunitárias e associações profissionais. Com escalas originais de 4 pontos, após a construção de um índice por procedimento somatório padronizamos um índice que varia de 0 a 10 . Atentos à possibilidade dos partidos agirem como uma estrutura específica de recrutamento para o comparecimento eleitoral, também introduzimos como controle uma variável que indica a frequência (em uma escala de 4 pontos) a reuniões de partidos ou grupos políticos.

O trabalho de Carreras e Irepoglu (2013) também identifica importante relação entre confiança política e comparecimento eleitoral ao analisar dados do LAPOP para a América Latina, especialmente da confiança no processo eleitoral. Incluímos então como controle uma medida que combina os níveis de confiança no Congresso Nacional, no Governo Federal e nos Partidos Políticos. As três medidas com 
escalas originais de 7 pontos foram somadas e o índice resultante teve sua amplitude alterada para variar entre 0 e 10. A medida específica de confianças nas eleições foi também inserida, em sua escala original de 7 pontos. Para além dessas variáveis julgamos pertinente incluir também medidas de avaliação econômica egotrópica e sociotrópica (ambas com escalas de 5 pontos) em razão de estudos anteriores terem identificado que o não comparecimento ou os votos brancos e nulos podem ser também expressão do descontentamento do eleitorado (Borba, 2008).

Por fim, consideramos relevante incluir uma medida da adesão dos indivíduos à democracia (dicotômica, 1=democracia é preferivel a qualquer outra forma de governo), principalmente em razão da sua associação recorrente com a prática de ações políticas contestatórias e o refluxo do engajamento em formas tradicionais (Norris, 2007; Inglehart e Welzel, 2009), mas também em função da expectativa de que maior adesão à democracia seja um indicador da existência de vínculos subjetivos do eleitor com o funcionamento das instituições democráticas (Almond e Verba, 1963). Dessa forma, maior adesão viria acompanhada de maior comparecimento, independente do contexto de voto obrigatório ou facultativo.

Em razão da disponibilidade de dados sobre as medidas psicométricas apresentadas anteriormente, foram considerados 15 países na análise, divididos em dois blocos em razão da obrigatoriedade ou não do comparecimento.

\section{RESULTADOS E DISCUSSÃO}

Como é possível verificar abaixo (Tabela 1) apenas uma reduzida minoria dos países em questão adota o voto facultativo: Colômbia, El Salvador e Venezuela. Como os percentuais dos blocos demonstram, o comparecimento tende a ser maior no contexto de obrigatoriedade, corroborando trabalhos anteriores que aferiram a relevância desse instituto (Ribeiro, Borba e Silva, 2015), mas há casos que contrariam essa regra. No bloco dos países que adotam a obrigação legal temos, por exemplo, a Costa Rica com o menor percentual de todas as 15 nações. No bloco dos "facultativos" temos El Salvador com percentual superior ao de alguns países que adotam alguma obrigação constitucional. 
Tabela 1

Comparecimento eleitoral por país e bloco

(América Latina, 2010)

\begin{tabular}{llll}
\hline Obrigatório & $\%$ & Facultativo & $\%$ \\
\hline Argentina & 75,2 & Colômbia & 60,2 \\
Bolívia & 89,2 & El Salvador & 79,3 \\
Brasil & 83,4 & Venezuela & 68,6 \\
Chile & 93,7 & & \\
Costa Rica & 58 & & \\
Equador & 92,7 & & \\
Guatemala & 69 & & \\
México & 71 & & \\
Panamá & 81,8 & & \\
Paraguai & 66,8 & & \\
Peru & 80 & & \\
República Dominicana & 76,1 & & \\
Uruguai & 93,5 & & \\
Bloco & 80,9 & Bloco & \\
\hline Fonte: Lapop Brasil 2010. & & &
\end{tabular}

As duas primeiras colunas da Tabela 2 apresentam os resultados dos modelos contendo a medida de extroversão, mas antes de relatar o seu impacto é interessante avaliarmos a situação dos controles. Confirmando resultados de pesquisas anteriores, o comparecimento é mais provável entre mais escolarizados (Verba, Schlozman e Brady, 1995; Ribeiro e Borba, 2015), mais velhos (Blais, Gidengil e Nevitte, 2004) e inseridos de forma mais intensa em redes de associativismo, isso em ambos os blocos de países (com voto obrigatório e facultativo). Considerando a Teoria do Voluntarismo Cívico (Verba, Schlozman e Brady, 1995), todavia, os efeitos redutores do interesse por política em todos os países chamam a atenção, pois indicam que essa mobilização cognitiva para a política tende a reduzir a probabilidade de comparecimento. Uma possível explicação para esse resultado pode ser encontrada nas teorias da cidadania crítica (Inglehart e Welzel, 2009; Norris, 2007), que encontraram associações entre maior interesse e sofisticação política e a crítica aos mecanismos tradicionais de ação política, como o voto. A transposição desse raciocínio para os 
casos em análise, entretanto, demandaria combinar essa medida de interesse com outros atributos que caracterizam o cidadão crítico, o que escapa dos limites de nossa pesquisa.

A medida de confiança nas eleições, como seria possível antecipar, eleva a probabilidade de comparecimento nos dois blocos de países, com uma tendência de maiores efeitos nos contextos facultativos. A confiança nas instituições (congresso, governo e partidos), todavia, teve efeitos apenas no bloco com voto obrigatório, reduzindo a redução da probabillidade desse comportamento.

As medidas de avaliação apresentam sinais divergentes, já que a relativa à situação econômica nacional apresentou efeito positivo apenas nos contextos de obrigatoriedade, enquanto a que diz respeito à situação pessoal apresenta efeito positivo nesse bloco, mas negativo no grupo composto pelos países que facultam o comparecimento. Esse resultado apresenta problemas para as hipóteses do descontentamento, já que, sobretudo no caso da medida egotrópica, o impacto é o contrário do esperado, sugerindo que a satisfação econômica pessoal está associada à alienação eleitoral.

Os efeitos do democratismo corroboram resultados de investigações prévias (Verba, Schlozman e Brady, 1995; Norris, 2007; Inglehart e Welzel, 2009), ainda que sejam estatisticamente significativos apenas para o grupo com voto obrigatório. É importante destacar alguns efeitos diferenciais de preditores como o associativismo partidário e o sexo, que se mostraram preditores relevantes apenas no bloco que faculta o comparecimento aos seus cidadãos. Nesses contextos em que a obrigatoriedade não existe, a ligação dos cidadãos com as instituições partidárias e grupos políticos eleva de forma considerável a chance desse comportamento ativo (23\%, considerando o controle de todas as demais variáveis). Esse resultado contradiz importante literatura que tem apontado para as mudanças nas funções partidárias, com perda de relevância da dimensão da mobilização política (Menegóz, 2000; Mair, 2003; Dalton, 2012). Nesses contextos encontramos também o efeito positivo de ser mulher, indicando que são as eleitoras as que mais comparecem quando não são obrigadas, o que contrasta fortemente com a persistente desigualdade em termos de representação política entre os gêneros. 
Ednaldo Aparecido Ribeiro, Julian Borba

Tabela 2

Efeitos da Extroversão e da Conscienciosidade sobre o comparecimento (América Latina, 2010)

\begin{tabular}{|c|c|c|c|c|}
\hline & Obrigatório & Facultativo & Obrigatório & Facultativo \\
\hline Escolaridade & $1,07^{* * *}(, 006)$ & $1,05^{* *}(, 014)$ & $1,08^{* * *}(, 007)$ & $1,05^{* * *}(, 013)$ \\
\hline Idade & $1,06^{* * *}(, 007)$ & $1,06^{* * *}(, 005)$ & $1,06^{* * *}(, 003)$ & $1,06^{* * *}(, 005)$ \\
\hline Sexo & $1,01(, 055)$ & $1,32 * *(100)$ & $1,00(, 055)$ & $1,28^{*}(, 100)$ \\
\hline $\begin{array}{l}\text { Interesse por } \\
\text { Política }\end{array}$ & $0,84^{* * *}(, 032)$ & $0,88^{*}(, 058)$ & $0,84^{* * *}(, 032)$ & $0,88^{*}(, 058)$ \\
\hline $\begin{array}{l}\text { Eficácia Política } \\
\text { Subjetiva }\end{array}$ & $1,00(, 018)$ & $1,06 .(, 032)$ & $1,00(, 018)$ & $1,05^{*}(, 032)$ \\
\hline Associativismo & $1,19^{* * *}(, 020)$ & $1,19^{* * *}(, 039)$ & $1,19 * * *(, 020)$ & $1,19^{* * *}(, 039)$ \\
\hline $\begin{array}{l}\text { Associativismo } \\
\text { Partidário }\end{array}$ & $1,06(, 050)$ & $1,23^{*}(, 102)$ & $1,06(, 050)$ & $1,23^{*}(, 010)$ \\
\hline $\begin{array}{l}\text { Confiança } \\
\text { Política }\end{array}$ & $0,95^{* *}(, 017)$ & $1,02(, 032)$ & $0,95^{* *}(, 016)$ & $1,02(, 032)$ \\
\hline $\begin{array}{l}\text { Confiança nas } \\
\text { Eleições }\end{array}$ & $1,06^{* *}(, 018)$ & $1,13^{* * *}(, 035)$ & $1,07^{* *}(, 018)$ & $1,13^{* * *}(, 035)$ \\
\hline $\begin{array}{l}\text { Avaliação Econ. } \\
\text { Sociotrópica }\end{array}$ & $1,20^{* * *}(, 041)$ & $0,99(, 075)$ & $1,19^{* * *}(, 042)$ & $0,98(, 076)$ \\
\hline $\begin{array}{l}\text { Avaliação Econ. } \\
\text { Egotrópica }\end{array}$ & $1,09 * *(, 034)$ & $0,84^{* *}(, 060)$ & $1,09 * *(, 034)$ & $0,84^{* *}(, 060)$ \\
\hline Eficácia Política & $1,00(, 018)$ & 1,06. $(, 032)$ & $1,00(, 018)$ & $1,05(, 032)$ \\
\hline Democratismo & $1,16^{*}(, 062)$ & $1,12(, 116)$ & $1,17^{*}(, 062)$ & $1,11(, 117)$ \\
\hline Extroversão & $1,06^{* * *}(, 012)$ & $1,10^{* *}(, 030)$ & - & - \\
\hline $\begin{array}{l}\text { Conscienciosi- } \\
\text { dade }\end{array}$ & - & - & $1,04^{*}(, 016)$ & $1,11^{* * *}(, 091)$ \\
\hline Intercepto & $0,12^{* * *}(, 244)$ & $0,04^{* * *}(453)$ & $0,15^{* * *}(245)$ & $0,04^{* * *}(, 467)$ \\
\hline $\mathrm{N}$ & 9864 & 2371 & 9861 & 2364 \\
\hline
\end{tabular}

Fonte: Lapop Brasil 2010.

Modelo logístico com erros padronizados robustos apresentados entre parênteses.

Nenhum dos preditores registrou valor de VIF maior do que 5, conforme estatísticas de colinearidade no Anexo 1.

Códigos de Signif.: $0^{\star * * * \prime} 0,001^{\star * * \prime} 0,01^{\star * \prime} 0,05^{\prime \prime}$ ' $0,1^{\prime \prime} 1$

Tratando das nossas hipóteses, o efeito do traço da extroversão em ambos os contextos é estatisticamente significativo, confirmando assim $\mathrm{H} 1$. O efeito de $6 \%$ sobre a probabilidade de comparecimento, 
que inicialmente pode ser visto como reduzido, deve ser avaliado à luz da escala em que o traço é medido, variando de 0 a 10 . Desta forma, a diferença entre um eleitor que apresenta o menor valor de extroversão e aquele que atinge o máximo ultrapassa a marca dos 50\%. Nestes termos, esse efeito é comparável ao produzido pela escolaridade, que comporta escala menor e é bem maior do que o da eficácia política. No contexto latino-americano os extrovertidos, portanto, possivelmente considerem o ato de votar como um meio de expressar suas opiniões e posições políticas, uma tendência associada a esse traço. A despeito da natureza individual e solitária do voto (Gerber et al., 2011), que poderia desfavorecer a sua prática entre indivíduos que apreciam a interação interpessoal, essa é uma modalidade de ação política acionada poresse grupo de eleitores.

A confirmação de $\mathrm{H} 2$ ocorre quando verificamos que os efeitos no bloco dos países com voto facultativo são maiores. Quando não há o nivelamento dos cidadãos pela obrigatoriedade, aqueles que podemos chamar de extrovertidos são os mais propensos a comparecerem nos locais de votação. Ainda que o voto seja um ato essencialmente individual, a extroversão demonstra assim que se trata de um preditor bastante relevante para o ativismo político em geral.

Passando aos modelos com a conscienciosidade, H3 é confirmada em ambos os contextos, indicando que, na medida em que as pontuações nessa escala psicométrica aumentam, também aumenta a probabilidade de comparecimento. $\mathrm{O}$ mecanismo pelo qual esse efeito ocorre passa pela maior sensibilidade dos indivíduos que manifestam esse traço em relação às normas sociais e aos comportamentos socialmente desejados (Costa e Mccrae, 2003). Conforme alertam Gerber et al. (2008), como o ato de votar é fortemente carregado dessa desejabilidade, é compreensível que esse efeito ocorra. O impacto neste caso é bastante próximo do verificado no modelo com a extroversão e, da mesma forma, a sua avaliação deve levar em conta a extensão da escala. Pode-se falar, então, de uma relação considerável entre a pontuação nesse componente da personalidade e o ato de comparecer aos locais de votação.

Nossa última hipótese, H4, foi igualmente confirmada, já que o impacto nos contextos de voto facultativo é maior do que no bloco de países que adotam a obrigatoriedade. $\mathrm{O}$ impacto nesse grupo menor de países é de 11\%, ou seja, mais que o dobro. Como antecipamos na 
seção anterior, acreditamos que isso se deva ao nivelamento moral que a obrigatoriedade produz, já que independentemente da internalização ou não das normas sociais, todos são obrigados a comparecer, ainda que as punições sejam bastante variáveis entre as unidades nacionais. Onde o voto é facultativo, o incentivo moral é o único que imediatamente incide sobre a decisão de comparecer, sendo assim mais provável que aqueles que se preocupam com o cumprimento do dever cívico se envolvam.

\section{CONSIDERAÇÕES FINAIS}

O estudo testou o efeito dos traços de personalidade sobre o comparecimento eleitoral. Os resultados aqui apresentados somam-se a outros trabalhos desenvolvidos pelos autores sobre a relação entre tais traços e outras dimensões do comportamento político, em especial o comportamento de protesto (Ribeiro e Borba, 2015).

Aqui propusemos uma abordagem que buscou verificar os efeitos de dois traços (extroversão e consciensiosidade) em sua relação com o comparecimento às eleições. Tais variáveis foram controladas por outras medidas individuais tradicionalmente utilizadas nos estudos de comportamento político.

Os resultados confirmaram as quatro hipóteses formuladas na parte inicial do artigo, o que fornece novas evidências empíricas para as teorias do comportamento político que recorrem às estruturas da personalidade como eixo explicativo. Para além desta constatação, cabe aqui explorar (mesmo que hipoteticamente) os mecanismos pelos quais as dimensões ligadas à extroversão e conscienciosidade exercem influência na predisposição do indivíduo de comparecer ao local de votação.

Quanto à primeira, considerando que as pessoas portadoras desses traços interagem com o número maior de pessoas, é de esperar que elas desenvolvam maiores vínculos interpessoais ou com organizações sociais e políticas. Existe vasta literatura na Ciência Política que explora justamente os efeitos das redes sociais para a participação eleitoral (Magalhães, 2008), e este parece ser o mecanismo pelo qual tal traço influencia positivamente no comparecimento. Seria importante em estudos futuros explorar justamente a relação entre extroversão e sociabilidade, por um lado e, por outro, seus efeitos (individuais e mútuos) sobre o comparecimento. Da mesma forma, seria im- 
portante explorar a relação (e interação) entre a referida característica psicológica e dimensões relacionadas à localização do indivíduo na estrutura social. Por exemplo, em que medida o efeito da extroversão é potencializado ou não pela escolaridade na hora do voto? Ou seja, esse traço dependeria ou não de elementos relacionados à sofisticação política para se manifestar em maior intensidade?

Quanto à conscienciosidade, a influência sobre o voto parece ser justamente pela característica da internalização de normas sociais, conforme formulado por Gerber et al. (2008). Tal dimensão está diretamente ligada ao nível ou estágio do desenvolvimento moral dos indivíduos (que define o padrão pelo qual as normas são aceitas), mas é de se supor que os efeitos sejam cumulativos e por isso os impactos maiores da referida dimensão em países com voto obrigatório. Em outras palavras, seria de supor que, em contextos de voto facultativo, a conscienciosidade influencia a parcela do eleitorado que esteja localizada em níveis mais elevados de desenvolvimento moral. Para usar a linguagem de Gerber, em tais contextos iriam votar aqueles que cumprem a norma a partir da dimensão do reconhecimento ou da internalização. Já no contexto do voto obrigatório, além desses dois perfis de conscienciosidade, entrariam também os conscenciosos por "coerção", que em geral, constituem a parte mais numerosa das sociedades.

É claro que, ao explorar tais perfis de obediência às normas, estamos saindo do plano propriamente individual da personalidade e trazendo o contexto à tona. Como na dimensão anterior, acreditamos que seja impossível explorar tais traços sem ter que verificar a localização do indivíduo na estrutura social. Em outras palavras, a relação entre sujeito e norma é perpassada pela dimensão moral e cognitiva, como o próprio Gerber reconhece. A tarefa para estudos futuros é justamente explorar tais dimensões na sua devida complexidade. 


\section{NOTAS}

1. As bases genéticas dessas diferenças individuais têm sido demonstradas em trabalhos como o de McCrae et al. (2001), que identificaram que essa ordem de fatores explica mais de 50\% da variação nessa estrutura interna. Yamagata et al. (2006), por sua vez, através de estudos com gêmeos na América do Norte, Europa e Ásia, verificaram que essa influência se mantém constante entre as diferentes regiões geográficas, sustentando a hipótese de uma estrutura genética universal da estrutura de personalidade independente de processos de aprendizado ou aculturação.

2. Apesar de escalas mais amplas possibilitarem a identificação de nuances em traços subsidiários, Mondak (2010) apresenta uma interessante revisão de publicações que testaram os rendimentos de escalas menores e chegaram à conclusão de que os instrumentos baseados em apenas cinco ou dez itens são igualmente confiáveis na identificação dos cinco grandes traços.

3. Informações técnicas sobre as amostras nacionais podem ser obtidas na página eletrônica do projeto http://www.vanderbilt.edu/lapop/. 


\section{REFERÊNCIAS BIBLIOGRÁFICAS}

ADORNO, Theodor et al. (1950), The authoritarian personality. New York: Harper.

ALMOND, Gabriel; VERBA, Sidney. (1963), The civic culture. Political atitudes and democracy in five nations. Princeton: Princeton University Press.

BARRICK, Murray; MOUNT, Michael. (1991), “The Big Five personality dimensions and job performance: a meta-analysis". Personnel Psychology, v. 44, pp. 194-230.

BLAIS, André. (2006), "What affects voter turnout?" Annual review of political science, v. 9, pp. 111-125.

BLAIS, André; GIDENGIL, Elisabeth; NEVITTE, Neil. (2004), “Where does turnout decline come from?". European Journal of Political Research, v. 43, pp. 221-236.

BLAIS, André; LABBÉ-St-VINCENT, Simon. (2011), "Personality traits, political attitudes, and the propensity to vote". European Journal of Political Research, v. 50, n. 3, pp. 395-417.

BOLGER, Niall; SCHILLING, Elizabeth. (1991), "Personality and the problems of everyday life: the role of neuroticism in exposure and reactivity to daily stressors". Journal of Personality, v. 59, pp. 335-386.

BOOTH-KWLEY, Stephanie; VICKERS, Ross. (1994), “Associations between major domains of personality and health behavior". Journal of Personality, v. 62, pp. 281-298.

BORBA, Julian. (2008), "As bases sociais e atitudinais da alienação eleitoral no Brasil”. Revista Debates, v. 2, pp. 134-157.

BURKE, Ronald; MATTHIESEN, Stig Berge; PALLESEN, Stale. (2006), “Workaholism, organizational life and well-being of Norwegian nursing staff". Career Development International, v. 11, n. 5, pp. 463-477.

CARRERAS, Miguel; CASTAÑERA-ANGARITA, Néstor. (2004), "Who votes in Latin America? A test of three theoretical perspectives". Comparative Political Studies, v. 47, n. 8 , pp. 1079-1104.

CARRERAS, Miguel; IREPOGLU, Yasemin. "Trust in elections, vote buying, and turnout in Latin America". Electoral Studies, v. 32, n. 4, pp. 609-619.

CATTELL, Raymond. (1956), "Validation and Interpretation of the 16 P. F. Questionnaire". Journal of Clinical Psychology, v. 12, n. 3, pp. 205-214.

CEPALUNI, Gabriel; HIDALGO, Daniel. (2016), “Compulsory voting can increase political inequality: Evidence from Brazil”. Political Analysis, v. 24, n. 2, pp. 273-280.

CONNOLLY, James; KAVANAGH, Erin; VISWES-VARAN, Chockaligam. (2007), “The convergent validity between self and observer ratings of personality: a meta- analytic review". International Journal of Selection and Assessment, v. 15, nº 1, pp. 110-17.

COSTA, Paul; McCRAE, Robert. (2003), Personality in adulthood. A five-factor theory perspective. New York: Guilford.

DALTON, Russell. (2012), The Apartisan American. Washington: CQ Press. . (2015), The good citizen. Washington: CQ Press. 


\section{Ednaldo Aparecido Ribeiro, Julian Borba}

DE LEON, Fernanda; RIZZI, Renata. (2016), "Does forced voting result in political polarization?". Public Choice, v. 166, n. 1-2, pp. 143-160.

DENNY, Kevin; DOYLE, Orla. (2008), "Political interest, cognitive ability and personality: determinants of voter turnout in Britain". British Journal of Political Science, v. 38, pp. 291-310.

DUDLEY, Nicole et al.. (2006), "A meta-analytic investigation of conscientiousness in the prediction of job performance". Journal of Applied Psychology, v. 91, pp. 40-57.

ERIKSON, Erick. (1969), Gandhi's truth. New York: Norton.

EYSENCK, Hans Junger. (1947), Dimensions of personality. London: Routledge. . (1954), The psychology of politics. New York: Routledge, Chapman e Hall.

FOWLER, James; KAM, Cindy. (2006), "Patience as a political virtue: delayed gratification and turnout". Political Behavior, v. 28, pp. 113-128.

FRANKLIN, Daniel; GRIER, Eric. (1997), “Effects of motor voter legislation - voter turnout, registration, and partisan advantage in the 1992 presidential election". American Politics Quarterly, v. 25, n. 1, pp. 104-117.

FRIEDMAN, Henry et al. (1993), "Does childhood personality predict logevity?" Journal of Personality and Social Psychology, v. 65, pp. 176-185.

GALLEGO, Aina. (2010), “Understanding unequal turnout: education and voting in comparative perspective". Electoral Studies, v. 29, n. 2, pp. 239-248.

GEORGE, Alexander; GEORGE, Juliette. (1964), Woodrow Wilson and Colonel House: a personality study. New York: Dover.

GERBER, Alan; GREEN, Donald; LARIMER, Christopher. (2008), "Social Pressure and Voter Turnout: Evidence from a Large-Scale Field Experiment". American Political Science Review, v. 102, $\mathrm{n}^{\circ}$ 1, pp. 33-48.

GERBER, Alan et al. (2011), "Personality traits in the political arena". Annual Review of Political Science, v. 14, pp. 265-87.

GEYS, Benny. (2006), "Explaining voter turnout: a review of aggregate-level research". Electoral Studies, n. 25, pp. 637-663.

GOLDBERG, Lewis. (1992), "The development of markers for the Big-Five factor structure". Psychological Assessment, v. 4, n. 1, pp. 26-42.

GREENSTEIN, Fred. (2003), The George W. Bush presidency: an early assessment. Baltimore: Johns Hopkins University Press.

HIGHTON, Benjamin. (1997). "Easy registration and voter turnout". Journal of Politics, v. 59 , n. 2, pp. 565-575.

HOLBEIN, John; RANGEL, Marcos. (2016), "Does voting have upstream and downstream consequences? Evidence from compulsory voting in Brazil". Working Paper. Disponível em https://poseidon01.ssrn.com/delivery.php?ID=05410510406606 802309706508808711309905602103504808701706511511411312701709011 208210312404109704111401603200710512101702707401511801804608603501910411507 
800812309507303605007310012200812412108407911607712210200106912612109102111 $3098008071028103096122082 \mathrm{eEXT}=$ pdf Acesso em fevereiro de 2019.

HORN, Josh; NELSON, Carnot; BRANNICK, Michael. (2004), "Integrity, conscientiousness and honesty". Psychological Reports, v. 95, pp. 27-38.

HUANG, Tsai-Jung; CHI, Shu-Cheng; LAWLER, John. (2005), “The relationship between expatriates' personality traits and their adjustment to international assignments". International Journal of Human Resource Management, v. 16, n. 2, pp. 1656-1670.

INGLEHART, Ronald; NORRIS, Pippa. (2003), Rising tide: gender equality and cultural change around the world. Cambridge: Cambridge University Press.

INGLEHART, Ronald; WELZEL, Christian. (2009), Modernização, mudança cultural e democracia: a sequência do desenvolvimento humano. São Paulo: Francis.

JACKSON, Robert. (2000), "Differential influences on participation in midterm versus presidential elections". Social Science Journal, v. 37, n. 3, pp. 385-402.

LAURSEN, Brett; PULKKINEN, Lea; ADAMS, Ryan. (2002), “The antecedents and correlates of agreeableness in adulthood". Developmental Psychology, v. 38, pp. 591-603.

MAGALHÃES, Pedro. (2008), "Redes sociais e participação eleitoral em Portugal”. Análise Social, v. XLIII, n. 3, pp. 473-504.

MAIR, Peter. (2003), “Os partidos políticos e a democracia”. Revista Análise Social, v. 38, n. 167 , pp. $277-293$.

McCRAE, Robert et al. (2001), "Sources of Structure: genetic, environmental, and artifactual influences on the covariation of personality traits". Journal of Personality, v. 69, pp. 511-535.

MENEGÓZ, Giovanni. (2000), “Questões políticas e partidárias do Brasil de hoje". Revista Política Democrática, a. 1, n. 0, pp. 95-118.

MONDAK, Jeffery. (2010), Personality and the fundations of political behavior. Cambridge: Cambridge University Press.

MONDAK, Jeffery et al. (2010), "Personality and civic engagement: an integrative framework for the study of trait effects on political behavior". American Political Science Review, v. 104, n. 1, pp. 85-110.

MONDAK, Jeffery; HALPERIN, Karen. (2008), “A Framework for the Study of Personality and Political Behavior". British Journal of Political Science, v. 38, pp. 335-362.

MOSS, Simon et al. (2007), "Maintaining a open mind to closed individuals: the effects of resource availability and leadership style on the association between openness to experience and organizational commitment". Journal of Research in Personality, v. 41, pp. 259-275.

MUTZ, Diana. (2002), "The consequences of cross-cutting networks for political participation". American Journal of Political Science, v. 46, pp. 838-855.

NORRIS, Pippa. (2007), "Political activism: new challenges, new opportunities". In: C. Boix; D. Stokes (eds.), The oxford handbook of comparative politics. Oxford: Oxford University Press, pp. 628-652. 


\section{Ednaldo Aparecido Ribeiro, Julian Borba}

POSNER, Richard; RASMUSEN, Eric. (1999), "Creating and enforcing norms, with special reference to sanctions". International Review of Law and Economics, v. 19, pp. 369-382.

PULFORD, Briony; SOHAL, Harjit. (2006), "The influence of personality on HE students' confidence in their academic abilities". Personality and Individual Differences, v. 41, pp. 1409-1419.

RENSHON, Stanley. (1995), The Clinton presidency: campaigning, governing and the psychology of leadership. Bolder: Westview.

RIBEIRO, Ednaldo; BORBA, Julian. (2015), "Protesto político na América Latina: tendências recentes e determinantes individuais". Opinião Pública. v. 21, n. 1, pp.188-216.

RIBEIRO, Ednaldo; BORBA; Julian; SILVA; Rafael. (2015), “Comparecimento eleitoral na América Latina: uma análise multinível comparada". Revista de Sociologia e Política, v. 23, n. 54 , pp. $91-108$.

ROKEACH, Milton. (1960), The open and closed mind: investigation into the nature of belief systems and personality systems. New York: Basic Books.

SCHEFF, Thomas. (2000), "Shame and the social bond: a sociological theory". Sociological Theory, v. 18, pp. 84-99.

STENNER, Karen. (2005), The authoritarian dynamic. Cambridge: Cambridge University Press.

TUPES, Ernest; CHRISTAL, Raymond. (1961), Recurrent personality factors based on trait ratings USAF ASD technical report n. 61-97. Lackland Air Force Base. Texas: U.S. Air Force.

ULBIG, Stacy; FUNK, Carolyn. (1999), "Conflict avoidance and political participation". Political Behavior, v. 21, pp. 265-282.

VERBA, Sidney; SCHLOZMAN, Kay; BRADY, Henry. (1995), Voice and equality: civic voluntarism in American Politics. Cambridge: Harvard University Press.

WEITZ SHAPIRO, Rebecca; WINTERS, Matthew S. (2011), "The link between voting and life satisfaction in Latin America.". Latin American Politics and Society v. 53, n. 4, pp. 101-126.

WINTER, David. (2003), “Measuring the motives of political actors at a distance”. In: J. Post (ed.). The psychological assessment of political leaders: with profiles of Saddan Hussein and Bill Clinton. Ann Arbor: University of Michigan Press, pp. 153-177.

YAMAGATA, Shinji et al. (2006), "Is the genetic structure of human personality universal? a cross-cultural twin study from North America, Europe, and Asia". Journal of Personality and Social Psychology, v. 90, n. 6, pp. 987-998. 


\section{APÊNDICE}

Anexo 1

Valores de VIF para teste de Multicolinearidade

\begin{tabular}{|c|c|c|c|c|}
\hline & Obrigatório & Facultativo & Obrigatório & Facultativo \\
\hline Escolaridade & 1,238 & 1,400 & 1,226 & 1,339 \\
\hline Idade & 1,177 & 1,203 & 1,185 & 1,201 \\
\hline Sexo & 1,021 & 1,027 & 1,023 & 1,036 \\
\hline Interesse por Política & 1,148 & 1,205 & 1,146 & 1,200 \\
\hline Eficácia Política Subjetiva & 1,122 & 1,129 & 1,124 & 1,131 \\
\hline Associativismo & 1,069 & 1,042 & 1,069 & 1,039 \\
\hline Associativismo Partidário & 1,134 & 1,090 & 1,133 & 1,089 \\
\hline Confiança Política & 1,486 & 1,746 & 1,478 & 1,736 \\
\hline Confiança nas Eleições & 1,418 & 1,586 & 1,418 & 1,568 \\
\hline $\begin{array}{l}\text { Avaliação Econômica } \\
\text { Sociotrópica }\end{array}$ & 1,147 & 1,202 & 1,148 & 1,200 \\
\hline $\begin{array}{l}\text { Avaliação Econômica } \\
\text { Egotrópica }\end{array}$ & 1,212 & 1,198 & 1,211 & 1,196 \\
\hline Eficácia Política & 1,122 & 1,129 & 1,124 & 1,131 \\
\hline Democratismo & 1,020 & 1,023 & 1.019 & 1,023 \\
\hline Extroversão & 1,045 & 1,160 & - & - \\
\hline Conscienciosidade & - & - & 1,022 & 1,075 \\
\hline
\end{tabular}

Fonte: Lapop Brasil, 2010. 


\section{RESUMO \\ Personalidade e Comparecimento Eleitoral na América Latina: Efeitos de Características Psicológicas Individuais em Contextos de Obrigatoriedade}

Estudos sobre comparecimento eleitoral têm se dedicado à identificação dos condicionantes desse comportamento focalizando fatores de natureza estrutural, como o nível de desenvolvimento econômico das nações e características do sistema político, enquanto outros destacam variáveis individuais, como atributos sociodemográficos e atitudinais. Algumas pesquisas pioneiras têm recentemente investigado o impacto de características individuais de natureza psicológica sobre o comparecimento em democracias consolidadas com voto facultativo. Procurando contribuir para a compreensão desse fenômeno, o presente artigo apresenta resultado de pesquisa que procurou identificar os efeitos dessas características psicológicas sobre o comparecimento eleitoral nas jovens democracias latino-americanas que, entre outras particularidades institucionais, apresentam distinções quanto à obrigatoriedade do comparecimento. Utilizando dados do Latin American Public Opinion Project para um conjunto de 17 países da região, os resultados encontrados apontam para a relevância dessa dimensão psicológica individual para o comparecimento, com impactos distintos em contextos de voto facultativo e obrigatório.

Palavras-chave: comparecimento eleitoral; personalidade; América Latina

\section{ABSTRACT \\ Personality and Electoral Attendance in Latin America: Effects of Individual Psychological Characteristics on Mandatory Contexts}

Studies on electoral attendance have been devoted to identifying the constraints of this behavior by focusing on structural factors such as the level of economic development of nations and characteristics of the political system, while others highlight individual variables such as sociodemographic and attitudinal attributes. Some groundbreaking research has recently investigated the impact of individual psychological characteristics on attendance in democracies with optional voting. Seeking to contribute to the understanding of this phenomenon, this article presents the result of research that sought to identify the effects of these psychological characteristics on electoral attendance in young Latin American democracies that, among other institutional particularities, have distinctions regarding the obligatory attendance. Using data from the Latin American Public Opinion Project for a set of 17 countries in the region, the findings point to the relevance of the individual psychological dimension in attendance, with distinct impacts on both optional and compulsory voting contexts.

Keywords: Electoral Attendance; Personality; Latin America 


\section{RÉSUMÉ \\ Personnalité et présence électorale en l'Amérique Latine: Les effets des caractéristiques psychologiques individuelles sur les contextes obligatoires}

Des études sur la présence électorale ont été consacrées à l'identification des contraintes de ce comportement en se concentrant sur des facteurs structurels, tels que le niveau de développement économique des nations et les caractéristiques du système politique, tandis que d'autres mettent en évidence des variables individuelles telles que les attributs sociodémographiques et attitudinaux. Des recherches novatrices ont récemment porté sur l'impact des caractéristiques psychologiques individuelles sur la participation dans les démocraties à vote facultatif. Dans le but de contribuer à la compréhension de ce phénomène, cet article présente des résultats de recherche visant à identifier les effets de ces caractéristiques psychologiques sur la présence électorale dans les jeunes démocraties latino-américaines, qui, entre autres particularités institutionnelles, distinguent la présence obligatoire. En utilisant les données du Latin American Public Opinion Project pour un ensemble de 17 pays de la région, les résultats soulignent la pertinence de cette dimension psychologique individuelle pour la participation, avec des impacts distincts sur les contextes de vote facultatif et obligatoire.

Mots-clés: Participation Électorale; Personnalité; Amérique Latine

\section{RESUMEN}

Personalidad y Concurrencia Electoral en América Latina: Efectos de Características Psicológicas Individuales en Contextos de Obligatoriedad

Estudios sobre participación electoral se han dedicado a la identificación de los condicionantes de ese comportamiento focalizando factores de naturaleza estructural, como el nivel de desarrollo económico de las naciones y características del sistema político, mientras que otros destacan variables individuales, como atributos sociodemográficos y de actitud. Algunas investigaciones pioneras han investigado recientemente el impacto de características individuales de naturaleza psicológica sobre la concurrencia electoral en democracias consolidadas con voto facultativo. Buscando contribuir a la comprensión de ese fenómeno, el presente artículo presenta resultados de investigación que buscó identificar los efectos de esas características psicológicas sobre la concurrencia electoral en las jóvenes democracias latinoamericanas que, entre otras particularidades institucionales, presentan distinciones en cuanto a la obligatoriedad de la concurrencia. Utilizando datos del Latin American Public Opinion Project para un conjunto de 17 países de la región, los resultados encontrados apuntan a la 
Ednaldo Aparecido Ribeiro, Julian Borba

relevancia de esa dimensión psicológica individual para la concurrencia, con impactos distintos en contextos de voto facultativo y obligatorio.

Palabras clave: concurrencia electoral; personalidad; América Latina 